\title{
Uji Pasar Desain Furniture Rotan Untuk Pasar Global STUDI KASUS: PAMERAN IFEX 2018
}

\author{
Maitri Widya Mutiara ${ }^{1)}$, Agustinus Purna Irawan $^{2)}$ Eddy Supriyatna Marizar ${ }^{3)}$ \\ 1)Untar, Jakarta \\ 2)Untar, Jakarta \\ 3)Untar, Jakarta \\ Email: maitrim@fsrd.untar.ac.id \\ agustinus@untar.ac.id \\ eddys@fsrd.untar.ac.id
}

\begin{abstract}
Penelitian dalam pagelaran pameran desain furniture rotan merupakan upaya untuk mendapatkan respon kelayakan pasar dan produksi yang dihasilkan dari proses penciptaan desan furniture rotan. Pagelaran pameran ajang uji pasar yang relevan dalam menciptakan berbagai kontak baru. Di dalam konteks ini, kontak baru yang dimaksud adalah responden, yaitu pengunjung pameran (buyers) yang spesifik memahami dunia furniture. Jika kita mempunyai produk baru yang akan diluncurkan, pameran menjadi sarana peluncuran yang tepat, baik terhadap media dan audiens sasaran. Desain merupakan unsur sentral komunikasi (pemasaran). Penampilan produk, kemasannya, cara mengiklankannya, semua mempunyai peran dalam membangkitkan respon emosional dari seorang pelanggannya. Pagelaran pameran internasional merupakan salah satu luaran di dalam proses penelitian penciptaan desain furniture untuk pasar global. Hasil penciptaan desain tersebut wajib dipamerkan untuk mengamati kecenderungan respon pengunjung pameran (buyers) terhadap desain yang diciptakan. Adapun IFEX 2018 (Indonesia International Furniture Expo 2018) merupakan ajang pertemuan antara produsen dan pembeli asing dari berbagai negara. Pengunjung pameran sebagai responden adalah para pelaku bisnis furniture yang sangat memahami dunia furniture, termasuk desain furniture yang sesuai dengan "wants and needs" konsumennya di pasar global. Penelitian ini menggunakan metodologi penelitian kualitatif berbasis riset desain dan manajemen, dengan metode pengumpulan data melalui wawancara langsung dengan pengunjung pameran yang datang dari berbagai negara. Hasil dari penelitian ini berupa masukan kepada desainer yakni: desain kursi rotan dengan system yang baru yaitu "stacking" dan "knock-down". Pada furniture Knock-down perlu memperhatikan system konstruksi terutama dari segi estetis dan teknis.
\end{abstract}

Kata kunci: Desain, furniture, rotan, pameran, pasar global.

\section{PENDAHULUAN}

Pagelaran pameran internasional merupakan salah satu luaran di dalam proses penelitian penciptaan desain furniture untuk pasar global. Hasil penciptaan desain tersebut wajib dipamerkan untuk mengamati kecenderungan respon pasar / calon pembeli (buyers) terhadap desain yang diciptakan. Penelitian ini merupakan pendukung penelitian Dikti 2018. Adapun IFEX 2018 (International Furniture Expo 2018) merupakan ajang pertemuan antara produsen dan pembeli asing (buyers) dari berbagai negara.

Pengunjung pameran sebagai responden adalah para pelaku bisnis furniure yang sangat memahami dunia furniture, termasuk desain furniture yang sesuai dengan "wants and needs" konsumennya di pasar global. Biasanya, pameran IFEX dikunjungi 5000 sampai 10.000 pengunjung dari seluruh dunia. Momentum itulah yang layak menjadi sasaran penelitian pada pagelaran pameran desain furniture rotan ini.

Di sisi lain, Perguruan Tinggi sebagai lembaga pendidikan, penelitian dan pengabdian kepada masyarakat berkewajiban dan mempunyai tanggungjawab terhadap pertumbuhan dunia usaha dalam upaya meningkatkan daya saing pasar. Salah satu kontribusi perguruan tinggi adalah penciptaan desain untuk meningkatkan daya saing pasar.

Di dalam rangka meningkatkan daya saing industri furniture rotan Indonesia tersebut diperlukan pengembangan produk melalui 
penelitian dan penciptaan desain furniture untuk tujuan pasar global. Salah satu "ujung tombak" untuk meningkatkan daya saing dan nilai tambah dapat dilakukan melalui penciptaan desain tersebut. Bahkan berbagai instansi dan asosiasi memberikan sinyalemen bahwa kelemahan utama daya saing industri furniture adalah belum optimalnya pengembangan dan penciptaan desain. Oleh sebab itu diperlukan ujicoba pasar melalui pagelaran pameran.

Tampaknya, penyelenggaraan berbagai even pameran furniture Internasional di Jakarta dapat pula dijadikan indikator pagelaran furniture yang diakui dunia, terbukti dengan kehadiran para calon pembeli (buyers) yang berkunjung untuk memesan dan membeli produk furniture Indonesia. Bahkan, pemerintah telah mencanangkan agar industri furniture Indonesia dapat mencapai target lima milyar dollar Amerika selama lima tahun ke depan.

Hal itu membuktikan bahwa industri furniture Indonesia dapat dijadikan salah satu tulang punggung perekonomian. Selain sumber daya alam, sumber daya manusia yang terampil dalam bidang industri furniture rotan sudah menjadi tradisi yang mengakar turun-temurun. Bila dicermati, potensipotensi tersebut menjadi kekuatan bagi pengembangan industri furniture rotan di Indonesia. Namun demikian, kondisi industri furniture rotan Indonesia masih tampak belum memiliki nilai daya saing tinggi di dalam kancah bisnis furniture rotan di pasar global. Salah satu aspek yang mampu mendukung nilai daya saing adalah desain.

Daniel H. Pink pun telah menempatkan desain di urutan pertama dalam kecerdasan manusia sebagai high concept dan high touch. Saat ini adalah saat yang penting secara ekonomi dan berharga secara personal untuk menciptakan sesuatu yang indah, sedikit fantastis, dan menarik secara profesional (Pink, 2007: 71, 93). Esensinya bahwa penelitian, pengembangan dan penciptaan desain menjadi strategi "terdepan" dalam bisnis furniture, termasuk memperkenalkan desain furniture kepada konsumennya melalui pagelaran. pameran. Hal itu dilakukan untuk mengamati tingkat keberhasilan desain yang telah diciptakan pada penelitian tahap pertama pada program penelitian Dikti,

Desain-desain furniture rotan yang akan dipamerkan dirancang berdasarkan penelitian pasar global, sekaligus penelitian produksi. Penelitian dalam proses penciptaan desain berdasarkan pada hasil penelitian keinginan (wants) dan kebutuhan (needs) konsumen pasar global, khususnya Asia Pasifik. Oleh karena itu, penelitian dilakukan dengan pendekatan multidisiplin (studi desain, studi produksi rotan dan studi pemasaran global).

Penelitian pasar yang telah dilakukan bertujuan untuk merumuskan karakteristik desain yang berbasis pasar ekspor sebagai landasan penciptaan desain furniture rotan. Hasil penelitian dan penciptaan desain diaplikasikan sebagai produk industri, dipublikasikan dan dipasarkan secara internasional. Sebab, kini desain furniture telah menjadi perangkat daya saing di pasar global. Sebab, desain telah menjadi salah satu trend gaya hidup masyarakat dunia.

Di dalam rangka mengidentifikasi tanggapan konsumen terhadap desain dan produk yang akan ditampilkan secara visual itu diperlukan uji pasar global, salah satunya melalui sarana pameran IFEX 2018. Uji pasar dilakukan untuk desain-desain baru yang berlandaskan hasil penelitian pasar global. Di dalam konteks ini, desain-desain furniture 
rotan yang dirancang berdasarkan penelitian pasar global itu diwujudkan dalam bentuk prototype skala 1:1.

Dengan demikian pengembangan desain yang berbasis riset pasar layak dilakukan, sebagai upaya untuk mendekatkan karakteristik desain dengan harapan konsumen. Oleh sebab itu, untuk mengetahui sejauhmana tanggapan konsumen terhadap desain dan produk yang diciptakan ini diperlukan sarana pameran. Sebab, pameran (khususnya IFEX) merupakan salah satu sarana yang ideal untuk melakukan uji coba pasar produk, terutama produk furniture rotan dengan desain yang baru. Program ini juga sebagai bagian dari upaya untuk pengembangan desain furniture rotan yang berbasis pasar global (ekspor).

Adapun hasil penelitian penciptaan desain tahap pertama dan kedua yang akan dipamerkan memiliki keunggulan sebagai berikut: Pertama, desain dibuat berdasarkan penelitian pasar global dan penelitian produksi di sentra industri rotan Cirebon dan Solo. Kedua, sistem konstruksi dibuat knock down system (sistem bongkar pasar) dan stacking system (sistem susun), sehingga efisien dan efektif dalam kemasan dan pengangkutan dalam kontainer. Ketiga, knock down system dalam industri furniture rotan masih jarang, bahkan langka, sehingga memiliki nilai pembeda. Keempat, seluruh desain dibuat kreasi baru dan berbeda dengan yang sudah ada di pasaran dan bebasis riset, sehingga memiliki nilai kreasi, nilai lebih, dan nilai daya saing tersendiri. Kelima, desain dibuat dengan landasan akademis yang dapat dipertanggungjawabkan secara ilmiah. Keenam, Penelitian digarap secara multidisipin oleh tenaga akademis (doktor dan profesor) yang ahli di bidangnya masing- masing. Ketujuh, desain dan prototype telah diujicobakan dalam focus group discussion (FGD) bersama pelaku industri, praktisi, desainer, akademisi, anggota asosiasi usaha mebel, pakar produksi rotan, dan pakar pemasaran ekspor di Yogyakarta. Kedelapan, seluruh desain dalam proses untuk didaftarkan ke Direktorat HKI, khususnya perlindungan hak kekayaan intelektual bidang desain industri. Oleh sebab itu, hasil penciptaan desain furniture rotan pada tahap pertama dan tahap kedua layak untuk dipamerkan dan diujicoba pasar.

Pameran merupakan bagian dari program pemasaran. Di dalam berbagai teori pemasaran secara klasik, pameran masuk dalam promotion mix, yaitu bagian dari program personal selling, yang bersentuhan dengan komunikasi pemasaran. Menurut Tom Brannan (2004:83, 84) dalam bukunya "Integrated Marketing Communications" terungkap jelas bahwa pameran sengaja dirancang agar dapat diketahui masyarakat luas. Pameran mungkin merupakan "mid point" dan sangat baik untuk menciptakan berbagai kontak baru.

Di dalam konteks ini, kontak baru yang dimaksud adalah responden, yaitu pengunjung pameran (buyers) yang spesifik memahami dunia furniture. Lebih lanjut Brannan (2004: 85) mengungkapkan bahwa jika kita mempunyai produk baru yang akan diluncurkan, pameran menjadi sarana peluncuran yang tepat, baik terhadap media dan audiens sasaran.

Di dalam konteks desain, Brannen (2004: 76) memperjelas bahwa desain merupakan unsur sentral komunikasi (pemasaran). Penampilan produk, kemasannya, cara mengiklankannya, semua mempunyai peran dalam membangkitkan respon emosional dari seorang pelanggannya. 
Hal itu berhubungan erat dengan teori rethinking marketing yang mengungkapkan bahwa "marketing thinking and practice are in a state of change, redirection, and refocus. Conventional marketing approaches have been turned on their heads by a variety of new techniques, methods, and theories." (Schindehutte, Morris dan Pitt, 2008: xvii). Salah satu fokus pemasaran adalah pameran desain yang disajikan secara praktis, menampilkan metode penelitiannya dan pengembangan desain secara sistematik.

Adapun metode menuju uji pasar dalam pemeran berhubungan pula dengan studi pendahuluan yang telah dilaksanakan dalam proses penciptaan desain sejak tahun 1988 dan sebagian dengan pendaftaran Hak Desain Industri. Selain itu, mengikuti even pameran nasional dan internasional, kemudian melakukan penelitian tentang desain furniture ekspor, desain furniture di Jawa, terutama di Yogyakarta, Jepara, Klender, maupun Cirebon. Penelitian trend desain furniture dunia pada pameran internasional di Shanghai menghasilkan temuan trend desain furniture tahun 2015 (Marizar, 2015: 24-27). Hasil yang diperoleh dari studi pendahuluan itu ditemukan bahwa desain furniture di era globalisasi cenderung universal, nyaris sama di seluruh dunia, bentuk sederhana, praktis, massal, mudah, murah, dan cenderung tanpa ornamen itu dijadikan acuan, pedoman, dan peta jalan untuk proposal penelitian ini.

Adapun state of art untuk mencapai hasil tertinggi di dalam penelitian penciptaan ini adalah (1). Untuk mendapatkan tanggapan konsumen melalui uji pasar terhadap keunggulan produk dengan desain baru yang dibuat berdasarkan penelitian pasar (RISET TAHUN KEDUA), (2). Untuk mendapatkan tanggapan konsumen melalui uji pasar terhadap karakteristik desain furniture rotan yang ditujukan untuk pasar Asia Pasifik, khususnya China, Jepang, dan Korea Selatan (RISET TAHUN KEDUA). (3). Untuk memberikan pengetahuan dan pencerahan kepada masyarakat, khususnya produsen dan konsumen furniture dalam konteks penciptaan desain furniture rotan secara industrial, (4). Untuk ajang promosi Universitas Tarumanagara di tingkat internasional.

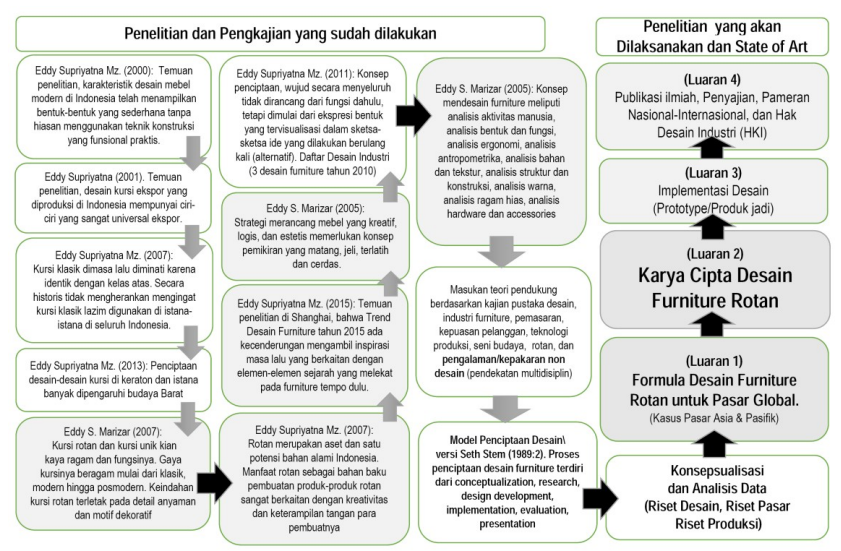

Diagram 2.

Peta Jalan (Road map) Penelitian Penciptaan Desain Furniture Rotan, salah satu luaran adalah Pagelaran Pameran Internasional.

(Sumber: Eddy S. Marizar, 2017)

\section{METODE}

Penelitian ini akan menggunakan metodologi penelitian kualitatif (Gummesson, 1991: 1-5) yang berbasis riset desain dan manajemen dengan pendekatan multidisiplin (Kartodirdjo, 1993: 87). Bidang keilmuan yang akan dipinjam meliputi desain industri, seni rupa terapan, ilmu manajemen, teknologi industri, dan ilmu budaya.

Penelitian kualitatif tidak meneliti suatu lahan kosong, tetapi peneliti menggalinya (Brannen, 1997: 13). Penelitian kualitatif selalu beranjak dari teori dan fakta sebagai studi kasus berdasarkan situasi tertentu 
(Brannen, 1997: 13,16). Penelitian kualitatif akan menggunakan informan sebagai tim penggalian data. Penggalian data dilakukan di arena pameran IFEX 2018 yang diselengarakan pada tanggal 9-12 Maret 2018 di Jakarta.

Adapun target responden minimal 50 pengunjung (buyers) dari berbagai negara. Hasil respon dari buyers ini dijadikan bahan evaluasi penciptaan desain furniture rotan untuk pasar ekspor.

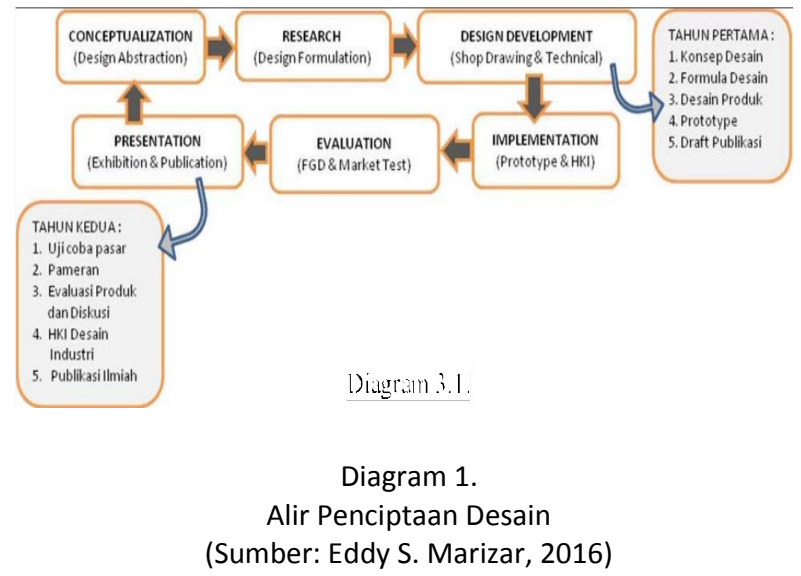

\section{HASIL DAN PEMBAHASAN}

Saat pameran berlangsung, tim peneliti dan tim di lapangan berhasil mendapatkan sejumlah responden yang berasal dari berbagai kalangan yakni:

- Buyer asing

- Produsen Furniture rotan maupun kayu

- Tren reader

- Akademisi

- Dsb

Adapun poin-poin pertanyaan yang diberikan kepada responden, adalah sebagai berikut:

- Apakah pernah melihat produk sejenis?

- Produk manakah yang menurut anda paling anda sukai
- Menurut anda, apakah yang membuat produk tersebut lebih baik daripada yang lain?

- Apakah ada masukan untuk model produk tersebut?

- Adakah model lain yang anda sukai?

- Kenapa?

- Apakah ada masukan untuk model lain tsb?

- Apakah anda memiliki ketentuan terkait dengan model kursi ini?

Tujuan dari penelitian ini adalah untuk menemukan keinginan pasar dalam hal ini deasin kursi rotan dengan sistem baru yakni "stacking" dan "knock down" yang diinginkan buyers dari internasional. Dengan adanya penelitian ini, peneliti akan melakukan beberapa perbaikan rencana desain terkait, terutama perbaikan di sistem konstruksi yang akan mempengaruhi tampilan visual di beberapa pertemuan sambungan.

Pertanyaan - pertanyaan diatas berlaku baik untuk model "stacking chair" maupun pada "knock down chair". 


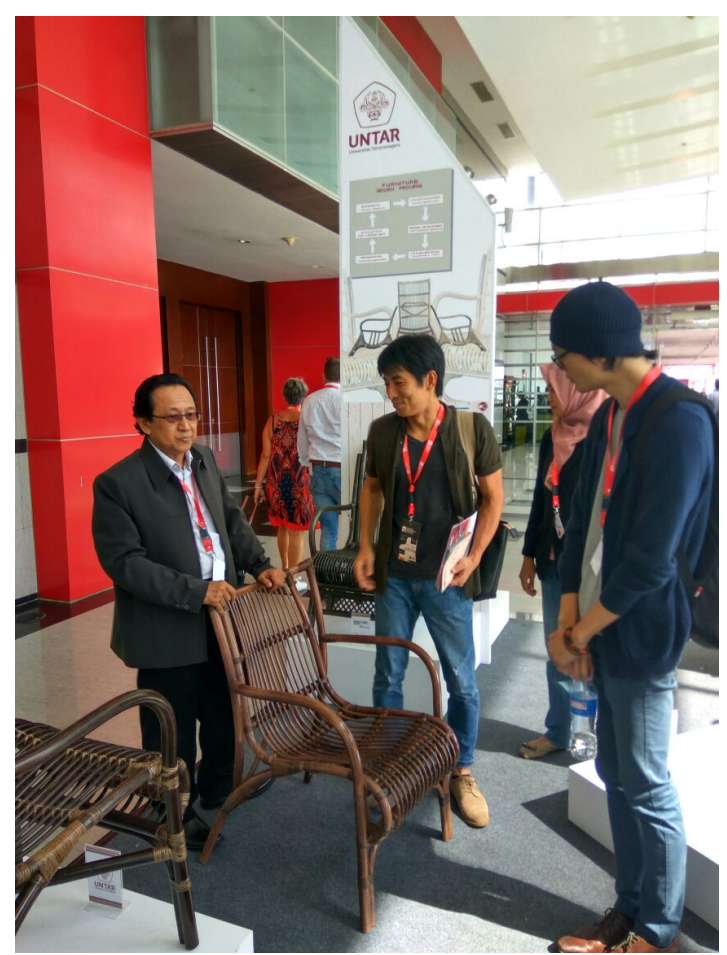

Gambar 1.

Suasana pameran pada saat buyer berdiskusi dengan peneliti.

(Sumber: dok. Tim peneliti, 2018)

Secara garis besar kursi Rotan "Stacking" maupun "knock down" masih belum dikenal oleh market, beberapa responden memiliki minat tinggi untuk kedua jenis kursi rotan ini belum termasuk model-model yang ada. Minat tinggi ini dapat dinilai dari adanya produsen furniture lokal yang ingin bekerjasama, buyer asing yang meminta price list dan ingin membeli kedua jenis kursi rotan. Selain itu peneliti mendapatkan masukan mengenai estetika kursi serta ukuran dan finishing yakni bahwa baut sebaiknya tidak terlihat pada rancangan kursi stacking, sementara finishing yang ada saat ini untuk knock-king dinilai akan cepat lecet. Sehingga dengan demikian masih membutuhkan desain dan finishing yang lebih baik lagi.

\section{SIMPULAN}

Tujuan dari penelitian ini adalah untuk menemukan keinginan pasar dalam hal ini desain kursi rotan dengan sistem baru yakni "stacking" dan "knock down" yang diinginkan buyers dari internasional. Dengan adanya penelitian ini, peneliti akan melakukan beberapa perbaikan rencana desain terkait, terutama perbaikan di sistem konstruksi yang akan mempengaruhi tampilan visual di beberapa pertemuan sambungan.

\section{UCAPAN TERIMA KASIH}

Tim peneliti mengucapkan terima kasih kepada pihak-pihak yang telah membantu dalam penelitian ini yaitu: Lembaga Penelitian dan Pengabdian Masyarakat Untar, Dyandra Promosindo, Tim Pelaksana Pameran IFEX 2018, dan Fakultas Seni Rupa dan Desain Universitas Tarumanagara.

\section{DAFTAR PUSTAKA}

Brannan, Tom. (1995). "A Practical Guide to Integrated Marketing Communications". Kogan Page.

Pink, Daniel H. (2007). Misteri Otak Kanan Manusia. Terj. Rusli. Jogjakarta: Think Jogjakarta.

Gummesson, Evert. (1991). Qualitative Methods in Management Research. London: Sage Publications. 
Kartodirdjo, Sartono. (1993). Pendekatan IImu Sosial dalam Metodologi Sejarah. Jakarta:

PT. Gramedia Pustaka Utama.

Marizar, Eddy Supriyatna. (2015)."Trend Desain Furniture di Era Pasar Global (Studi Kasus: The 20th Shanghai International Furniture Show $2014 \quad$ di China."Furnicraftoday.Jakarta: Asosiasi Mebel dan Kerajinan Nasional. Edisi Maret, hal. 24-27. 